University of Nebraska - Lincoln

DigitalCommons@University of Nebraska - Lincoln

USDA National Wildlife Research Center - Staff Publications
U.S. Department of Agriculture: Animal and Plant Health Inspection Service

$4-2000$

REPELLENTS TO REDUCE CABLE GNAWING BY WILD NORWAY RATS

Stephen A. Shumake

USDA-APHIS-Wildlife Services

Ray T. Sterner

USDA-APHIS-Wildlife Services

Stanley E. Gaddis

USDA-APHIS-Wildlife Services

Follow this and additional works at: https://digitalcommons.unl.edu/icwdm_usdanwrc

Part of the Environmental Sciences Commons

Shumake, Stephen A.; Sterner, Ray T.; and Gaddis, Stanley E., "REPELLENTS TO REDUCE CABLE GNAWING BY WILD NORWAY RATS" (2000). USDA National Wildlife Research Center - Staff Publications. 838. https://digitalcommons.unl.edu/icwdm_usdanwrc/838

This Article is brought to you for free and open access by the U.S. Department of Agriculture: Animal and Plant Health Inspection Service at DigitalCommons@University of Nebraska - Lincoln. It has been accepted for inclusion in USDA National Wildlife Research Center - Staff Publications by an authorized administrator of DigitalCommons@University of Nebraska - Lincoln. 


\title{
REPELLENTS TO REDUCE CABLE GNAWING BY WILD NORWAY RATS
}

\author{
STEPHEN A. SHUMAKE, ${ }^{1}$ U.S. Department of Agriculture, Animal and Plant Health Inspection Service, National Wildlife \\ Research Center, Fort Collins, CO 80521, USA \\ RAY T. STERNER, U.S. Department of Agriculture, Animal and Plant Health Inspection Service, National Wildlife Research \\ Center, Fort Collins, CO 80521, USA \\ STANLEY E. GADDIS, U.S. Department of Agriculture, Animal and Plant Health Inspection Service, National Wildlife Research \\ Center, Fort Collins, CO 80521, USA
}

\begin{abstract}
Rodents gnaw communications and power cables, resulting in service interruptions, fires, and other safety concerns. Commensal rodents such as the Norway rat (Rattus norvegicus) have been implicated in many of these situations. Two chemical repellents (capsicum oleoresin-capsaicin and denatonium benzoate) at $2.0 \%$ mass/mass concentrations in a polybutene carrier (Indopol ${ }^{\mathbb{B}}$-control) were evaluated for repellent efficacy compared to a plastic mesh physical barrier material (Vexar ${ }^{\circledR}$ ) and the polybutene carrier (placebo) alone using groups of individually caged wild Norway rats. The materials were applied to short lengths of communications cable (RG-8U) with the repellents enclosed in electrical shrink tubing around the samples and the plastic mesh attached to the samples for 7 days of continuous rat exposure. Measures of damage taken after rat exposure included mass of cable material damaged, volume loss to gnawing, depth of gnaw penetration, width of gnawing, and a qualitative index of damage based upon visual appearance. Using a stepwise discriminant analysis, we found less damage $(P<0.05)$ using the volume loss measure (cc) for the capsaicin and for the denatonium groups than for the polybutane-carrier (placebo) group. Other measures of gnawing damage did not improve statistical comparisons of the repellents. For all 5 measures of damage, there was a consistent rank order pattern among the means with capsaicin $<$ denatonium $<\operatorname{Vexar}^{(3)}<$ Indopol $^{\circledR}$-control.
\end{abstract}

JOURNAL OF WILDLIFE MANAGEMENT 64(4):1009-1013

Key words: gnawing, rat, Rattus norvegicus, repellent, rodent.

Wild Norway rats cause extensive damage to agricultural crops and structures, as well as to wire and cable system installations (Cogelia et al. 1976, Colvin et al. 1998). Their primary damage to communications and power cable installations results from their habit of gnawing on objects to maintain and clear burrows and runways. As a result, they keep their incisors ground and sharpened. A few reports have been published dealing with gnawing in wild Norway rats and pocket gophers (Thomomys talpoides, Geomys bursarius) from the standpoint of cable damage (Howard 1953, Ramey and McCann 1997, Shumake et al. 1999), but the objectives of most rodent control studies are to define their negative economic impacts and to recommend a means for ridding the premises of all rodents. Certainly, wild rats cannot be tolerated inside buildings for health and safety reasons, and reducing local populations remains the main method for dealing with this species. However, the presence of rodents often goes undetected in structures for a considerable time

I E-mail: stephen.a.shumake@usda.gov and repellent chemicals that would protect cabling inside of building walls or under crawl spaces would be useful.

Several published reports are also available that describe gnawing by gophers and the testing of repellent materials to reduce gnawing to underground cables. Ramey and McCann (1997) reviewed research and development efforts to develop cable-gnawing repellents over the past 3 decades. A few of their cited published reports describe and define the gnawing damage incurred by gophers, the chemicals that produce repellent effects, and the cable covering materials that ensure physical resistance to rodent gnawing. One report (Welch 1954) described similar problems related to wild Norway rat gnawing behavior, protection of cables, and protection of food packaging materials. Recently, Shumake et al (1999) reported the development of an improved method for delivering chemical repellents to northern pocket gophers as they attempt to gnaw communications cable by using a plastic shrink tubing material for containing the chemicals. We evaluated the efficacy of 2 chemical repellents using plastic shrink 
tubing with wild Norway rats to deter their gnawing of communications cables in laboratory evaluations.

\section{MATERIALS AND METHODS \\ Animals}

Wild Norway rats $(n=45)$ were captured in live traps $2 \mathrm{~km}$ north of Loveland, Colorado, in 1997. Animals ( $17 \mathrm{M}$ and $28 \mathrm{~F}$ ) were kept under quarantine for 2 weeks after capture at the National Wildlife Research Center (NWRC) Animal Research Building (ARB). They were maintained individually in wire mesh cages on a diet of Purina Laboratory Rodent Chow (Purina Mills, St. Louis, Missouri, USA) with water available ad libitum throughout quarantine and testing. Animal colony room temperatures were maintained at $20-25^{\circ} \mathrm{C}$, but relative humidity level was not controlled (generally $<30 \%$ ). Overhead lighting was maintained on a $12-\mathrm{hr}$ schedule with room lights on from 0600 until 1800 MST.

\section{Cable Samples and Chemicals}

Lengths of coaxial communications cable (RG-8U) were obtained from a local Radio Shack vendor. Samples were rubbed with $10 \%$ laboratory ethanol to remove possible residues left from the extrusion process and then rinsed with deionized water and dried using clean paper towels. For exposure to wild rats, the cable was cut into $10.0-\mathrm{cm}$ lengths.

Capsicum oleoresin (CAS No. 8023-77-6) in red liquid form was purchased as a 1-L sample from Lot No. 46051 from Penta Manufacturing (Livingston, New Jersey, USA). Denatonium benzoate (CAS No. 3734-33-6) in white crystalline form was purchased as a 5-g sample from Lot No. 54H0218 from Sigma Chemical (St. Louis, Missouri, USA). Indopol ${ }^{\circledR}$ H-1900 polybutene (CAS No. 9003-29-6) clear liquid base material was obtained as a l-L sample from Lot No. U95A95U1 from Amoco Chemical (Naperville, Illinois, USA). Vexar ${ }^{\circledR}$ seedling protector plastic mesh tubes were obtained from Terra Tech (Eugene, Oregon, USA).

\section{Procedure}

Preliminary screening for cable-gnawing behavior involved the use of $10(35.3 \times 17.8 \times$ $17.8-\mathrm{cm}$ ) stainless steel bioassay cages for housing animals during the test. The same protocol for evaluating cable-gnawing behavior was used for all captured rats. A $17 \times 17-\mathrm{cm}$ stainless steel plate barrier was inserted across the width of each cage and held in place by stainless steel channeling at $24.1 \mathrm{~cm}$ of cage length. The barrier was used to allow the rats access to gnawing on cable samples. The barriers obstructed the animals from using approximately one-third of their original individual cage spaces. At a height of $2.5 \mathrm{~cm}$ above the cage floor on each steel barrier, a centered $5 \times 5$-cm opening was available to each rat. This opening was obstructed, however, by a $10-\mathrm{cm}$ horizontal length of 1.3$\mathrm{cm}$ o.d. coaxial cable (RG-8) attached to the sides of the plate opening with 18-gauge steel tying wire. Individual cable samples remained in the 10 cages for 10 days. Then, samples (labeled according to Norway rat cage identification number) were examined for damage. Daily damage assessments were descriptive in terms of depth and width of gnawing for each animal and scored on a 5-point scale corresponding to (1) no damage, (2) incisor teeth marks, (3) outer covering penetrated, (4) wires chewed through, and (5) cable chewed completely through.

From the screened animals, 24 were selected that demonstrated at least a Level 3 (outer covering penetrated) of gnawing on the samples within 3 days of exposure. Animals were randomly assigned to 4 groups of 6 rats. Cable treatments were as follows: Indopol ${ }^{\circledR}$ (carriercontrol), $2.0 \%$ capsaicin, $2.0 \%$ denatonium benzoate, and $\operatorname{Vexar}^{\circledR}$ plastic mesh. The first 3 treatments also incorporated heat-shrink plastic tubing as a means of containing $2.0 \mathrm{cc}$ of material surrounding the RG-8U cable samples and as a means for increasing the amount of oral-mucosal-buccal cavity contact by animals as they attempted to gnaw the cable samples. The shrink tubing $(1.27 \mathrm{~cm})$ was cut to length $(13$ $\mathrm{cm}$ ) and slipped over each 10-cm cable sample. Forced air from a laboratory heat gun (Model HG-301, Master Appliance, Racine, Wisconsin, USA) was then used to first shrink and seal 1 end of the cable samples. Then $2.0 \mathrm{cc}$ of a given agent was added to the interstitial area between the cable and the tubing with a 3.0 -cc plastic disposable syringe. Finally, the remaining ends of the tubing-cable samples were sealed with the heat gun and samples were attached to the stainless steel panels with steel tying wire. Vex$\operatorname{ar}^{\circledR}$ plastic mesh material was cut to size to wrap around each cable sample (about $7 \times 10 \mathrm{~cm}$ ) and attached to the sample and panel with tying wire. Rats were then offered unrestricted exposure to the samples for 7 days and several 
quantitative cable-damage measures were then taken for each cable sample: cable mass loss, depth of penetration, width of gnawing, and volume of material gnawed. We also qualitatively assessed cable damage.

\section{Analysis}

The utility of the 4 quantitative dependent variables to discriminate repellent effectiveness was explored using stepwise discriminant function analyses. Separate discriminant analyses of the measures were computed for the stepwise selection, forward selection, and backward elimination options of the STEPDISC Program (SAS Institute 1992). For 1 animal in the Vexar ${ }^{(8)}$ group, width and volume measures were not obtained due to sample loss. Mean group estimates were used for these 2 missing values.

When 1 measure was found to reliably discriminate the gnaw damage amounts among the 4 treatments, a 1-way analysis of variance (ANOVA; Winer 1971) for that measure was used to compare treatments using a PROC-GLMANOVA and Type 3 sums of squares (SAS Institute 1992). Significant main effects were then analyzed using a Student-Newman-Keuls procedure (SAS Institute 1992) to compare (a posteriori) pairs of treatments at the $P<0.05$ level.

\section{RESULTS}

\section{Screen for Cable Gnawing}

Of the 45 animals tested for cable gnawing, 7 animals severed the samples within 7 days of exposure. A considerable number of the animals $(n=8)$ failed to show any gnawing on the RG$8 \mathrm{U}$ cable, but the majority of animals $(n=25)$ showed a Level 3 or higher gnawing intensity that involved at least penetration of the outer covering without damage to inner cable wires. During screening, 20 animals showed a moderate degree of gnawing; for these 20 animals, the measured effects in terms of $\bar{x} \pm \mathrm{SD}$ were as follows: cable mass loss of $2.82 \pm 2.85 \mathrm{~g}$, gnaw depth of $3.00 \pm 3.03 \mathrm{~mm}$, gnaw width of $7.26 \pm 3.03 \mathrm{~mm}$, gnaw volume of $4.01 \pm 3.34$ $\mathrm{cc}$, and a final gnaw rating of $3.00 \pm 1.45$.

\section{Repellent Tests}

With the chemical repellents added to cable samples (Fig. 1), there were noticeable reductions in the measured mean damage levels when gnawing on the Indopol ${ }^{\circledR}$ H-1900 (placebo sample) cable segments was used for a comparison. The 5-point rating scores for the

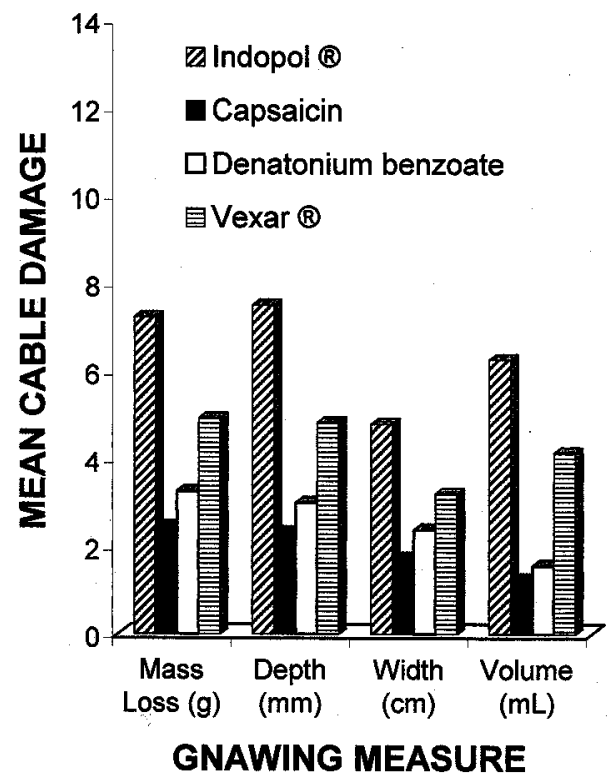

Fig. 1. Means for quantitative measures of wild Norway rat cable-gnawing damage for 3 repellent treatments versus a placebo control material (Indopol ${ }^{\circledR}$ ) on samples of commercial RG-8 coaxial cable exposed over 7 days.

placebo, Vexar capsaicin, and denatonium groups were $3.67 \pm 0.75,3.00 \pm 1.29,2.30 \pm$ 1.89 , and $2.50 \pm 1.38$, respectively.

Results of the 3 STEPDISC analyses were essentially identical; analyses of the dependent measures showed that volume (cc) of cable loss alone was most discriminative of gnawing damage by the rats. Inclusion of this variable into the function accounted for a maximum $69 \%$ of the variance.

The volume measure, when used in a univariate ANOVA, indicated treatment effects $\left(\mathbf{F}_{3,19}\right.$ $=5.50, P=0.007)$. Mean separation tests on the volume data indicated that both capsaicin and denatonium benzoate treatments produced relatively lower damage levels $(\boldsymbol{P}<0.05)$ when compared to the Indopol ${ }^{\oplus}$ (placebo) treatment. Neither chemical repellent, however, achieved statistically more damage reduction than Vexar ${ }^{(2)}$ treatment. For the volume measure, $\bar{x} \pm \mathrm{SD}$ (cc) damage levels were: capsaicin at $1.27 \pm$ 1.80 , denatonium at $1.57 \pm 1.46$, Vexar $^{\circledR}$ at 4.14 \pm 3.57 , and Indopol ${ }^{\circledR}$ at $6.27 \pm 1.75$. The order of damage levels based on means was found to be consistent for all 5 damage measures with capsaicin $<$ denatonium < Vexar $^{\boxplus}<$ Indopol $^{\circledast}$.

\section{DISCUSSION}

Avery (1997) has previously reported that by making the presence of a repellent more de- 
tectable, discriminable, and memorable one can improve effectiveness through a simple learning process such as classical conditioning where spatially and temporally correlated stimuli are repeatedly presented. The use of plastic tubing as a matrix for chemical repellents within a polybutene (Indopol ${ }^{\circledR}$ ) mixture offers a means for ensuring a high degree of oral, nasal, and buccal cavity contact by wild Norway rats as they attempt to gnaw cable material. The texture of this covering could provide the rats with a texture cue closely associated with the irritating effect of capsaicin or the bitter taste of denatonium. The latter detections are inferred to be mildly noxious to rats based on feeding exposure studies.

In a previous study using northern pocket gophers (Shumake et al. 1999) the repellent effects of both capsaicin and denatonium on gnawing appeared stronger than those exhibited by wild Norway rats in the current study. Capsaicin, for example, was shown to produce $95 \%$ less gnawing on all quantitative measures (volume, depth, width, and mass) when contained within the tubing over cable samples and compared to gnawing on placebo (control) cable samples. In our current study, capsaicin produced a significant and approximate $75-80 \%$ decrease on the mean volume measure compared to the placebo treatment. The other measures of cable damage for wild rats were lower (45-66\%) for capsaicin treatment compared to corresponding control samples, but these did not approach the repellent levels shown by gophers.

Reasons for this apparent species difference in repellent effect are uncertain. They could be related to behavioral, gross anatomical, or tastetrigeminal chemoreceptor differences between species. Both wild Norway rats and gophers can gnaw through dry material (paper, plastic, fiber) without detectable ingestion when toxic agents or chemical tracers are added as surface coatings (Welch 1954, Ramey and McCann 1997). The volume of cable lost to Norway rat gnawing provided the most sensitive measure for detecting damage reduction and this also provided the best measure for detecting repellent treatment effects in gophers. Volume of cable gnawed would also correlate to a high degree with functional loss of signals in communications cables (e.g., multi-conductor wire, fiber optic cables, or radio frequency cables).

Other potential sources of repellent chemicals such as predator urine or chemically iden- tified glandular extracts (Clapperton et al. 1989) could be evaluated with the tubing matrix and polybutene to examine and compare other natural, easily registered agents that could potentially discourage gnawing in a wide range of rodent species. Swihart et al. (1997) have demonstrated, for example, that woodchuck (Marmota monax) gnawing damage to trees can be reduced by $85 \%$ with topical applications of bobcat (Lynx rufus) urine. If this repellent effect is related to an innate avoidance of objects and areas that have been freshly urine-marked by predators, the material could have applications that could also be combined with an irritating capsaicin treatment to further reinforce rodent-gnawing repellence. The predator odor could, in fact, become a cue for the irritating effects of capsaicin treatment.

\section{MANAGEMENT IMPLICATIONS}

For Norway rats, capsaicin consistently produced the most repellent effects on cable gnawing. This repellent could be contained within plastic tubing surrounding cables in new installations, or plastic packet materials could be attached with adhesives to existing cable locations that have a history of rat damage. Costs of the chemicals in the Indopol ${ }^{\oplus}$ base would be a consideration because the carrier and high grade, food quality capsaicin cost about $\$ 1.05$ per $\mathrm{m}$ of cable in our study. The shrink tubing cost is another major consideration when purchased in small quantities-around $\$ 2.62$ per $\mathrm{m}$ of cable. However, other plastic materials that can be heat sealed are available at a cost of $\$ 0.10$ per $\mathrm{m}$ of cable and further evaluations are underway with alternate covering materials.

\section{ACKNOWLEDGMENTS}

We thank K. Hollenbeck for construction of the graphics, P. Groninger and R. Engeman for statistical support, and A. Dale for veterinary and laboratory animal care during the conduct of this study. We also appreciated review comments and suggestions for revision of the manuscript from C. Ramey, B. Petersen, M. Avery, and an anonymous reviewer.

\section{LITERATURE CITED}

AVERY, M. L. 1997. Repellents: integrating sensory modalities. Pages $11-17$ in J. R. Mason, editor. Repellents in wildlife management: proceedings of the second Denver Wildlife Research Center Special Symposium. Colorado State University, Fort Collins, Colorado, USA. 
Clapperton, B. K., E. O. Minot, and D. R. Crump. 1989. Scent lures from anal sac secretions of the ferret Mustela furo L. Journal of Chemical Ecology 15:291-308.

Cogelia, N. J., G. K. LAVoIe, and J. F. GLAHN. 1976. Rodent biting pressure and chewing action and their effects on wire and cable sheath. International Wire and Cable Symposium 25:117-124.

Colvin, B. A., Swift, T. B. ANd F. E. Fothergill. 1998. Control of Norway rats in sewer and utility systems using pulsed baiting methods. Proceedings of the Vertebrate Pest Conference 18:247253.

HowaRD, W. E. 1953. Tests of pocket gophers gnawing electrical cables. Journal of Wildlife Management 17:296-300.

RAMEY, C. A., AND G. R. MCCANN. 1997. Evaluating cable resistance to pocket gopher damage-A review. Pages 107-113 in C. D. Lee and S. E. Hygnstrom, editors. Thirteenth Great Plains Wildlife Damage Control Workshop Proceedings, Kansas State University, Agricultural Experiment Station and Cooperative Extension Service.
SAS INSTITUTE. 1992. SAS/ASSIST software: changes and enhancements. Version 6. SAS Institute, Cary, North Carolina, USA.

Shumake, S. A., R. T. Sterner, And S. E. Gaddis. 1999. Repellents to reduce cable gnawing by northern pocket gophers. Journal of Wildlife Management 63:1344-1349.

Swihart, R. K., M. J. Mattina, and J. J. PignatelLO. 1997. Pages 271-284 in J. R. Mason, editor. Repellents in wildlife management: proceedings of the second Denver Wildlife Research Center Special Symposium. Colorado State University, Fort Collins, Colorado, USA.

WELCH, J. F. 1954. Rodent control: a review of chemical repellents for rodents. Journal of Agricultural and Food Chemistry 2:142-149.

WINER, B. J. 1971. Statistical principles in experimental design. Second edition. McGraw-Hill, New York, New York, USA.

Received 15 November 1999.

Accepted 24 April 2000.

Associate Editor: Clark. 